\title{
A large-scale multicentre study of patient skin doses in interventional cardiology: dose-area product action levels and dose reference levels
}

\author{
${ }^{1} \mathrm{E}$ BOGAERT, MSc, ${ }^{1} \mathrm{~K}$ BACHER, MSc, ${ }^{1} \mathrm{~K}$ LEMMENS, MSc, ${ }^{2} \mathrm{M}$ CARLIER, MD, ${ }^{3} \mathrm{~W}$ DESMET, MD, PhD, ${ }^{4} \mathrm{X}$ DE \\ WAGTER, MD, ${ }^{5}$ D DJIAN, MD, ${ }^{6} \mathrm{C}$ HANET, MD, PhD, ${ }^{7} \mathrm{G}$ HEYNDRICKX, MD, ${ }^{8} \mathrm{~V}$ LEGRAND, MD, PhD, \\ ${ }^{9} \mathrm{Y}$ TAEYMANS, MD, PhD and ${ }^{1} \mathrm{H}$ THIERENS, PhD
}

\begin{abstract}
${ }^{1}$ Department of Medical Physics and Radiation Protection, Ghent University, Gent, ${ }^{2}$ Department of Interventional Cardiology, Hôpital St Joseph, Gilly, ${ }^{3}$ Universitair Ziekenhuis Gasthuisberg, Leuven, ${ }^{4}$ Algemeen Ziekenhuis Maria Middelares, St Jozef, Gent, ${ }^{5}$ Centre Hospitalier Namur, Namur, ${ }^{6}$ Cliniques Universitaires Saint Luc, Bruxelles, ${ }^{7}$ Onze Lieve Vrouwziekenhuis, Aalst, ${ }^{8} \mathrm{Centre}$ Hospitalier Universitaire, Liège, and ${ }^{9}$ Universitair Ziekenhuis, Gent, Belgium
\end{abstract}

\begin{abstract}
For 318 patients in 8 different Belgian hospitals, the entire skin-dose distribution was mapped using a grid of 70 thermoluminescence dosemeters per patient, allowing an accurate determination of the maximum skin dose (MSD). Dosearea product (DAP) values, exposure parameters and geometry, together with procedure, patient and cardiologist characteristics, were also registered. Procedures were divided into two groups: diagnostic procedures (coronary angiography) and therapeutic procedures (dilatation, stent, combined procedures (e.g. coronary angiography + dilatation + stent)). The mean value of the MSD was $0.310 \mathrm{~Gy}$ for diagnostic and $0.699 \mathrm{~Gy}$ for therapeutic procedures. The most critical projection for receiving the MSD is the LAO90 (left anterior oblique) geometry. In 3\% of cases, the MSD exceeded the 2 Gy dose threshold for deterministic effects. Action levels in terms of DAP values as the basis for a strategy for follow-up of patients for deterministic radiation skin effects were derived from measured MSD and cumulative DAP values. Two DAP action levels are proposed. A first DAP action level of $125 \mathrm{~Gy} \mathrm{~cm}{ }^{2}$ corresponding to the dose threshold of 2 Gy would imply an optional radiopathological follow-up depending on the cardiologist's decision. A second DAP

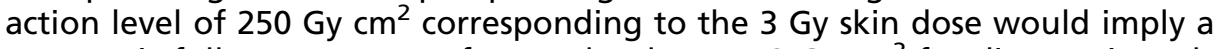
systematic follow-up. Dose reference levels $-71.3 \mathrm{~Gy} \mathrm{~cm} \mathrm{~cm}^{2}$ for diagnostic and $106.0 \mathrm{~Gy} \mathrm{~cm}^{2}$ for therapeutic procedures - were derived from the 75 percentile of the DAP distributions. As a conclusion, we propose that total DAP is registered in patient's record file, as it can serve to improve the follow-up of patients for radiation-induced skin injuries.
\end{abstract}

Received 23 August 2006 Revised 20 May 2008 Accepted 21 May 2008

DOI: $10.1259 / \mathrm{bjr} / 29449648$

(C) 2009 The British Institute of Radiology
The extensive exposure to X-rays during fluoroscopyguided procedures often provides high radiation doses to the patient's skin. Several radiation-induced skin injuries were described in the 1990s [1, 2]. By late 1994, the Food and Drug Administration (FDA) in the USA drew attention to this problem and later published advice on its website [3]. Koenig et al [4] describe more than 70 skin injuries in their review paper. These injuries varied from erythema, moist desquamation and ulceration to necrosis. The reported cases show that the vast majority of the overexposures took place in the catheterisation room during coronary angiography and interventions [5]. This is not unexpected as the number of cardiac interventions performed annually exceeds those of other interventional radiological procedures by an order of magnitude [5].

\footnotetext{
Address correspondence to: E Bogaert, Medical Physics and Radiation Protection, Ghent University, Gent, Belgium. E-mail: Evelien.Bogaert@ugent.be
}

Several recommendations for physicians working extensively with X-rays in interventional cardiology have been published in an attempt to reduce patient doses and to avoid radiation-induced injuries [6, 7]. Owing to the complexity of the procedures, radiationinduced skin injuries still occur, however, even with contemporary "state-of-the-art" dose-reducing X-ray systems and appropriate training of physicians.

As stated by the ICRP (International Commission on Radiological Protection), the risk of skin injuries has to be estimated for each individual patient in order to provide adequate follow-up and treatment of these injuries [8]. Dose thresholds of 2 Gy (onset of transient erythema), 3 Gy for maximum skin dose (MSD) or even as low as 1 Gy have been proposed [8]. Therefore, procedures for estimating and monitoring patient skin dose in daily practice need to be developed.

Several studies report skin doses received during interventional cardiology, which were mostly measured using film or a very limited number of thermolumines- 
cence dosemeters (TLDs) [9-11]. Owing to the complexity of irradiation geometries, which often involve two Xray tubes in a $C$-arm-type setting at different angles, it is not easy to predict which location on the patient's skin is going to receive the maximum dose. This implies that the total skin dose distribution has to be mapped so that MSD received can be measured. Dose distributions were measured by Suzuki et al [12] using colour-changing radiosensitive indicators, but for a restricted number of patients in only one catheterisation room.

Dose-area product (DAP) action levels are defined as levels of radiation that indicate skin exposures necessitating medical follow-up for possible radiation injuries. DAP action levels do not provide a guideline for optimising dose in relation to both medical benefit and the risk of injury, but dose reference levels (DRLs) do. Initial national DRL values can be derived from the 75 th percentile of the overall DAP distribution of patients undergoing a particular procedure. This method of DRL calculation is indicated when a small number of catheterisation rooms contribute to the study [13]. Comparing the local mean values with proposed national DRLs gives an idea of how the current practice in a hospital ranks with respect to patient dose.

In the present study, action levels derived from cumulative DAP values are proposed as indicators of skin dose. These were derived from the measurement of the entire skin dose distribution using a grid of TLDs, from which the MSD can be derived. In addition, initial values for Belgian national DRLs that are derived from diagnostic and therapeutic DAP distributions are proposed.

\section{Methods}

\section{Patients}

The patient group comprised 318 adult patients (221 male, 97 female, age range 29-89 years) who underwent cardiac catheterisation in eight Belgian hospitals during a period of 2 years (July 2003-July 2005). The hospitals were selected to be representative of current Belgian practice. Both university hospitals and private hospitals, all equipped with contemporary X-ray equipment, participated in the present study and were chosen to cover Belgium geographically. Patient demographics are summarised in Table 1 . In each hospital, about 40 patients in one catheterisation room were included in this study. The cardiac interventional procedures were divided into two groups: first, diagnostic coronary angiography, possibly combined with measurement of pulmonary capillary wedge pressure; second, therapeutic procedures, namely single or multiple percutaneous transluminal coronary angioplasty (PTCA) with or without single or multiple consecutive stenting, single or plural direct stenting and combined (diagnostic plus therapeutic) procedures. The procedures were performed by experienced cardiologists or medical doctors undergoing interventional cardiology training, all using their own protocols. A total of 200 diagnostic and 118 therapeutic procedures were included in this study.

\section{$X$-ray equipment and DAP meters}

The measurements were performed on different contemporary cardiac X-ray systems (Table 2). All tubes had an inherent filtration of $2.5 \mathrm{~mm} \mathrm{Al}$. X-ray equipment that was provided with "fixed filtration" insertion was distinguished from that with "variable filtration" insertion. A system with variable filtration adapts filtration thickness and material ( $\mathrm{Al}$ or $\mathrm{Cu}$ ) according to the thickness of the tissue being X-rayed, without the cardiologist's involvement. If the X-ray equipment has fixed filtration, the cardiologist must choose a filtration setting from a limited number of possible filtration settings. All possible filtration settings used in each hospital in either fluoroscopy or cinegraphy mode are given in Table 2. Generally, a combination of an aluminium filtration of a particular thickness and one or more copper filters of different thicknesses is used.

All X-ray tubes operated in a pulsed mode, and controlled tube voltage and anode current with automatic brightness control. All tubes were equipped with an integrated DAP meter (PTW). The DAP meters were calibrated in situ for different tube voltages, filtrations and modes (fluoroscopy or cinegraphy) with a $60 \mathrm{cc}$ ionisation chamber (Radcal, 10X5-60, Dutoit Medical) and $33 \times 41 \mathrm{~cm}$ Kodak X-Omat $\mathrm{V}$ films (Eastman Kodak) for determination of field size.

Table 1. Patient demographics and radiation dose parameters for diagnostic and therapeutic procedures

\begin{tabular}{|c|c|c|c|c|}
\hline & \multicolumn{2}{|c|}{ Diagnostic procedures } & \multicolumn{2}{|c|}{ Therapeutic procedures } \\
\hline & Mean (range) & Median & Mean (range) & Median \\
\hline \multicolumn{5}{|l|}{ Patient demographics } \\
\hline Number of males & 130 & & 91 & \\
\hline Number of females & 70 & & 27 & \\
\hline Weight of males $(\mathrm{kg})$ & 81 & & 82 & \\
\hline Weight of females $(\mathrm{kg})$ & 71 & & 71 & \\
\hline Age (years) & $67(29-86)$ & & $65(31-89)$ & \\
\hline $\mathrm{BMI}\left(\mathrm{kg} \mathrm{m}^{-2}\right)$ & $27(19-49)$ & & $28(20-47)$ & \\
\hline \multicolumn{5}{|c|}{ Measured and calculated radiation dose parameters } \\
\hline MSD (Gy) & $0.31(0.03-2.62)$ & 0.20 & $0.70(0.06-4.50)$ & 0.46 \\
\hline DAP $\left(\mathrm{Gy} \mathrm{cm}^{2}\right)$ & $55.7(2.71-265)$ & 43.8 & $81.5(10.3-404)$ & 65.4 \\
\hline$\%$ contribution of fluoro to DAP & $33(8-90)$ & & $50(9-91)$ & \\
\hline$\%$ contribution of cine to DAP & $67(8-90)$ & & $50(9-91)$ & \\
\hline
\end{tabular}

BMI, body mass index; DAP, dose-area product; MSD, maximum skin dose. 
Table 2. X-ray equipment used

\begin{tabular}{|c|c|c|c|c|c|c|c|c|c|}
\hline Hospital & $\begin{array}{l}\text { X-ray } \\
\text { system }\end{array}$ & $\begin{array}{l}\text { Mono/ } \\
\text { biplane }\end{array}$ & $\begin{array}{l}\text { Fluoro } \\
(p / s) \text { and } \\
\text { cine (f/s) }\end{array}$ & $\begin{array}{l}\text { Image } \\
\text { field }(\mathrm{cm})\end{array}$ & $\begin{array}{l}\text { Image } \\
\text { reception }\end{array}$ & $\begin{array}{l}\text { Date of } \\
\text { manufacture }\end{array}$ & Filtration & $\begin{array}{l}\text { Fluoro (mm Al/ } \\
\mathrm{mm} \mathrm{Cu})\end{array}$ & $\begin{array}{l}\text { cine }(\mathrm{mm} \mathrm{Al} / \\
\mathrm{mm} \mathrm{Cu})\end{array}$ \\
\hline 1 & $\begin{array}{l}\text { Philips } \\
\text { Integris BH } \\
5000\end{array}$ & $\mathrm{Bi}$ & $12.5-25$ & $23,17,14$ & II & 1999 & Fixed & $(1.5 / 0-0.3-0.5)$ & $(0 / 0)$ \\
\hline 2 & $\begin{array}{l}\text { Siemens } \\
\text { Coroskop }\end{array}$ & Mono & $12.5-25$ & $23,17,13$ & II & 1998 & Variable & $(0 / 0.2)$ & $(0 / 0.2-0)$ \\
\hline 3 & $\begin{array}{l}\text { Phillips BH } \\
\quad 3000\end{array}$ & $\mathrm{Bi}$ & $12.5-25$ & $23,18,14$ & II & 1996 & Fixed & $(1.5 / 0.1-0.2-0.4)$ & $(0 / 0)$ \\
\hline 4 & $\begin{array}{l}\text { Philips Allura } \\
\text { FD }\end{array}$ & Mono & $12.5-25$ & $25,20,15$ & FD & 2004 & Variable & $(1.5 / 0.1-0.4-0.9)$ & $(0 / 0)$ \\
\hline 5 & $\begin{array}{l}\text { Siemens } \\
\quad \text { Axiom Artis }\end{array}$ & $\mathrm{Bi}$ & $15-30$ & $25,20,16$ & FD & 2004 & Variable & $\begin{array}{c}(0 / 0-0.1-0.2- \\
0.3-0.6)\end{array}$ & $\begin{array}{l}(0 / 0-0.1-0.2-0.3- \\
\quad 0.6)\end{array}$ \\
\hline 6 & $\begin{array}{l}\text { Philips } \\
\text { Integris HM } \\
3000\end{array}$ & Mono & $12.5-25$ & $23,17,14$ & II & 1997 & Fixed & $(1.5 / 0.1-0.2-0.4)$ & $(0 / 0)$ \\
\hline 7 & $\begin{array}{l}\text { Siemens } \\
\text { Coroskop }\end{array}$ & Mono & $12.5-25$ & $23,17,13$ & II & 1996 & Variable & $(0 / 0.2)$ & $(0 / 0.2-0)$ \\
\hline 8 & $\begin{array}{l}\text { Siemens } \\
\text { Axiom Artis }\end{array}$ & Mono & $15-30$ & $25,20,16$ & FD & 2004 & Variable & $\begin{array}{c}(0 / 0-0.1-0.2- \\
0.3-0.6)\end{array}$ & $\begin{array}{l}(0 / 0-0.1-0.2-0.3- \\
0.6)\end{array}$ \\
\hline
\end{tabular}

$\mathrm{Bi}$, biplane; II, image intensifier; FD, flat detector; Mono, monoplane.

\section{Acquisition of exposure and procedure parameters}

Each irradiation geometry was determined by a set of two angles per tube, using the radiological convention for geometry setting: cranial and caudal rotations in the sagittal plane and left anterior oblique (LAO) and right anterior oblique (RAO) rotations in the transverse plane.

For each projection used in the cardiovascular intervention, geometry, tube potential, filtration settings per mode, number of frames, source to image detector distance, image detector field size, number of frames per second, tube current, pulse duration, and mode (fluoroscopy or cinegraphy) were registered. Cumulative DAP and DAP rate as a function of time during the procedure were registered online (Figure 1) by connecting the PTW DAP meter to a Diamentor M4 readout unit and a laptop. This allowed us to measure DAP contribution for each mode and projection.

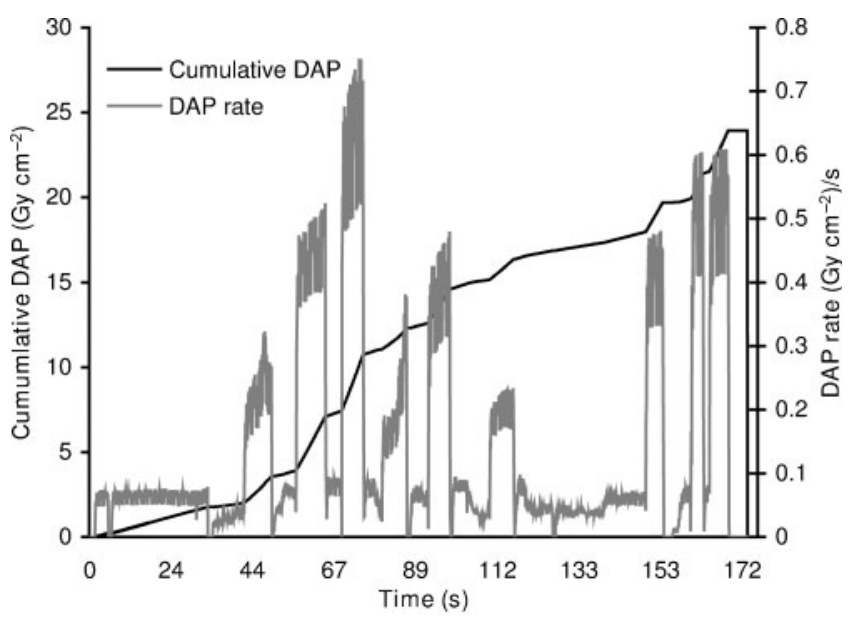

Figure 1. Typical output of the DAP registration program: cumulated DAP (dark line) and DAP rate (light line) as functions of time. This example shows nine cinegraphy runs with fluoroscopy in between.
After each intervention, the following information was recorded: complexity of the intervention (subjective score 1 to 3: "easy", "normal" and "difficult"), amount of contrast used, cardiologist's experience (specialist or trainee), standard protocol used for the intervention, and patient's data (gender, age, weight, height and chest circumference). The three-point scale for the complexity score was based on the duration of the procedures with respect to an equivalent procedure under normal circumstances, the number of lesions, the accessibility of the coronary arteries and the number of frames in one fixed position.

\section{Skin dose measurements}

A two-dimensional array of 70 TLDs (MTS-N type, Poland) covering the patient's chest was used to measure the skin-dose distributions of 318 patients in eight cardiological centres. A "wrap-around" was used to attach the TLDs to the patient's skin, which provided a grid of $30 \times 97.5 \mathrm{~cm}$ divided into squares of $7.5 \times$ $7.5 \mathrm{~cm}$. TLDs were wrapped in protective plastic and labelled with their position to enable reconstruction of the skin-dose distribution. The patient's chest was covered completely with the wrap-around, with the middle centred at the spine and the upper end at a height corresponding to the sternum. All patients were asked to keep their arms upwards with their hands behind the neck during the procedure. The wrap-around with the TLDs did not affect image quality as they were made of material (cotton for the wrap-around and $\mathrm{LiF}: \mathrm{Mg}$, Ti for the TLDs) that was not radio-opaque. Neither the wraparound nor the individual TLDs were visible on the radiographic cardiovascular images.

All TLDs were calibrated at the Standard Dosimetry Laboratory in Ghent (Belgium) at the beginning and at the end of the study at the beam quality that was used in situ. Read-out was performed with a Harshaw 3500 reader (Thermo Electron Corp.). For the study, TLDs were selected with calibration factors within a $5 \%$ range. The 
maximum difference between the calibration factors at the beginning and the end of the study was less than $10 \%$, which is the overall uncertainty in the measured MSD.

A graphical representation of the three-dimensional skin dose distribution was achieved by plotting TLD data on a mathematical cylindrical phantom representing the patient, taking into account the circumference of the wrap-around around the patient's chest (Figure 2).

DAP was calculated from the measured TLD skin dose and compared with measured DAP multiplied by a factor that takes into account the backscatter of the patient [14]. A very good correlation $(r=0.95)$ with a conversion factor of 1.03 was obtained, confirming the reliability of the DAP and TLD measurement sets.

\section{Statistical analysis}

As multiple factors can influence radiation dose measurements and calculations, we used a multifactor analysis of variance (ANOVA). Factors in the ANOVA design included the differences between hospitals, the difficulty of the procedure, system of beam filtration insertion and type of equipment (bi/monoplane, digital flat panel or conventional image intensifier). Levene's test was used to test the homogeneity of the variances between groups. A non-significant result of the Levene's test assured a correct application of the ANOVA analysis. Pillai's trace was used as a robust indicator of significance in the ANOVA analysis [15].

In cases where only two groups were compared, a non-parametric two-tailed Mann-Whitney test was performed. Correlations between groups were calculated by means of the non-parametric Spearman's rank correlation coefficient $(r)$. To calculate the regression coefficients of the relation between two quantities, linear regression analysis was performed using the LevenbergMarquardt algorithm. The relation between cumulative DAP and MSD was examined by the weighted least squares method, using heteroscedasticity for determination of weighting factors. Fitting and $p$-values were calculated using "the R-project" [16].

In all statistical calculations, a confidence interval of $95 \%$ was applied. Hence, a $p$-value $<0.05$ was considered as significant. All calculations were performed using the SPSS 12.0 software (SPSS, Chicago).

\section{Results}

\section{Maximum skin dose}

Radiation dose measurements are summarized in Table 1 . The mean value of MSD was $0.31 \mathrm{~Gy}$ and

\section{Contribution of frontal projections}

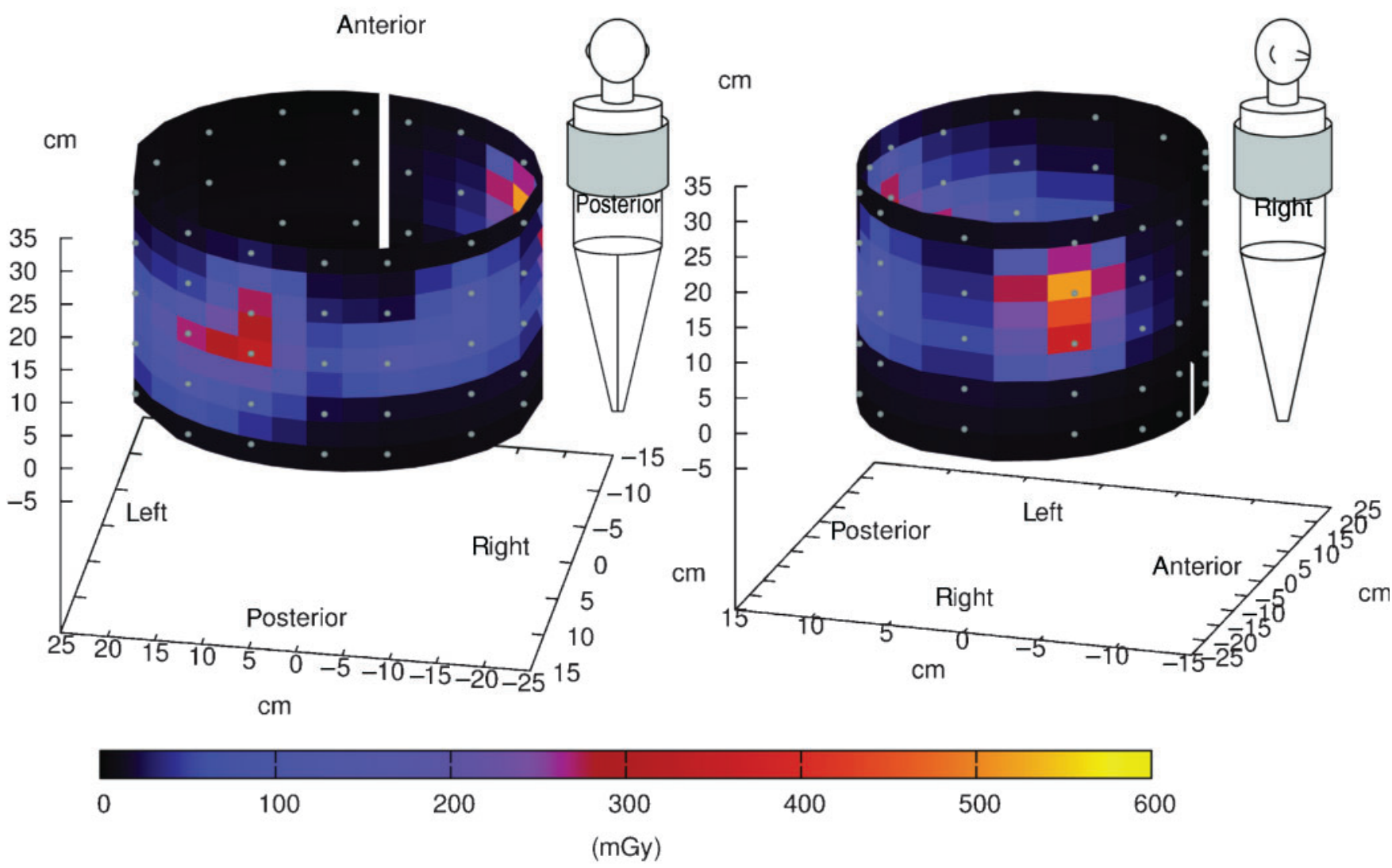

Figure 2. Three-dimensional representation of skin-dose distribution (mGy) for a coronary angiography in a biplane setting. TLD positions are indicated. Left: view from the back of the patient. Right: view from the right side of the patient. 
$0.70 \mathrm{~Gy}$ for diagnostic and therapeutic procedures, respectively. The difference between these mean values was significant at a level of $p=0.001$. The median MSDs were $0.20 \mathrm{~Gy}$ and $0.46 \mathrm{~Gy}$ for diagnostic and therapeutic procedures, respectively. Figure 3 shows MSD values (expressed as a histogram in intervals of $0.25 \mathrm{~Gy}$ ) for both diagnostic and therapeutic procedures with their mean values represented by vertical lines. A multifactor ANOVA was performed to check whether factors other than the type of procedure (diagnostic or therapeutic) affect the MSD. Both flat panel equipment and the use of biplane configurations did not significantly lower MSD ( $p=0.828$ and $p=0.626$, respectively). The lowest MSD values were recorded with systems equipped with variable filtration settings $(p=0.033)$. The MSD also depends significantly on the difficulty of the procedures $(p<0.001)$. In the three-point difficulty scale used in this study, levels 2 and 3 resulted in significantly greater MSD values than did the easiest (level 1) procedures.

ANOVA identified no significant differences in MSDs recorded in different hospitals $(p=0.171)$, partly because of large variations within in the MSD data set. Nonetheless, some clear trends were observed: in some hospitals higher mean MSDs could be explained by the continuous use of the fluoroscopy "high" mode for fluoroscopy filtration setting. This mode uses least beam filtration during exposure. In other hospitals, high doses could be explained by the training of doctors in percutaneous transluminal coronary angioplasty (PTCA) and stenting during the study period. Low mean MSDs are often related to "good practice" in terms of the amount of radiation used on a monoplane system. Alternatively, they may be explained by a local clinical practice in which coronary angiography is performed a few days before the therapeutic intervention, and is not therefore taken into account in the skin-dose distribution.

The angle of the projections under which the MSD was received by the patient could be deduced from the TLD measurements. These angles, measured in a transverse plane through the patient, are plotted as a histogram in Figure 4 . The sagittal angulations of the X-ray beam were not taken into account in this figure. The lateral projection (LAO90) is the most frequent projection leading to the MSD, in agreement with Kuon et al. [17].

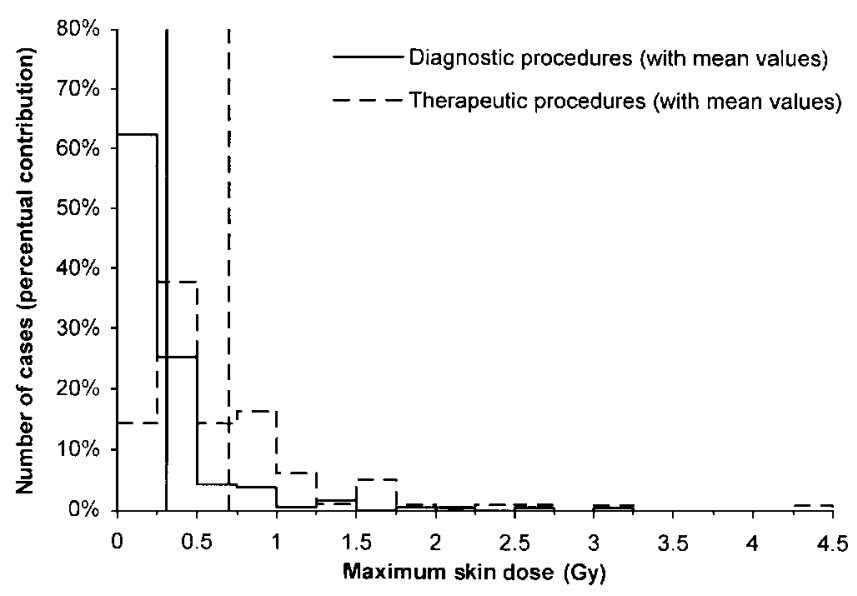

Figure 3. Histogram of maximum skin dose (Gy) for diagnostic (solid line) and therapeutic (dashed line) procedures. Mean values are indicated by vertical lines.
This projection involves a closer positioning of the tube to the patient's skin, and an increase in exposure is related to the fact that patients' chests are thicker in the lateral than in the anteroposterior dimension. The probability that the skin will be exposed to the MSD decreases steadily from lateral right to the centre of the back with a second prominent peak at the back left to the spine from the RAO30 projection. The angular distribution of the MSD indicates the necessity of using a large TLD set covering the whole chest for MSD determination in interventional cardiology.

For therapeutic procedures, the highest measured MSD was $4.50 \mathrm{~Gy}$, whereas for diagnostic procedures this value was $2.62 \mathrm{~Gy} .1 \%$ of the diagnostic procedures $(n=2)$ and $6 \%$ of the therapeutic procedures $(n=7)$ exceeded the threshold of 2 Gy for deterministic skin effects. An overview of these cases is given in Table 3. The therapeutic procedures were all "combined procedures" in which a diagnostic examination preceded a therapeutic intervention, except for case 2, which involved a merely therapeutic intervention. In three out of the nine cases in which the $2 \mathrm{~Gy}$ threshold was exceeded, a trainee was involved.

We also looked at the percentage contributions of fluoroscopy and cinegraphy to the DAP registered for the geometries that caused MSDs exceeding 2 Gy. In five of the nine cases, a long fluoroscopy projection was obviously responsible for the high skin dose (contribution $>75 \%$ ). Investigation of these exposures in detail shows that the main reason for high skin dosage is complexity of the examinations, with the most complex interventions necessitating a greater $\mathrm{X}$-ray exposure for the guidance of the catheter and imaging $(p<0.001)$. All patients with MSDs of 2 Gy and higher belonged to the high-difficulty group. According to our study, important factors that lead to high skin doses are high patient weight, prolonged use of one and the same projection (in both cinegraphy and fluoroscopy) and a relatively large distance between patient and image receptor, which reduces the distance between $\mathrm{X}$-ray source and patient in a C-arm setting.

\section{Dose-area product}

The mean value of DAP for diagnostic procedures was $55.7 \mathrm{~Gy} \mathrm{~cm}^{2}$, which differed significantly $(p<0.001)$ from that for therapeutic procedures $\left(81.5 \mathrm{~Gy} \mathrm{~cm}^{2}\right)$. The corresponding 75 th percentile values were $71.3 \mathrm{~Gy} \mathrm{~cm}^{2}$ and $106.6 \mathrm{~Gy} \mathrm{~cm}^{2}$ for diagnostic and therapeutic procedures, respectively. Table 4 gives an overview of mean DAP values for the different hospitals in the study, for comparison with the proposed DRLs. DAP values differ significantly among the hospitals $(p<0.001)$. Significant differences were also found between monoplane and biplane systems, with lower DAP values for monoplane systems $(p=0.026)$ (mean $59.6 \mathrm{~Gy} \mathrm{~cm}^{2}$ for monoplane versus $74.6 \mathrm{~Gy} \mathrm{~cm}^{2}$ for biplane systems). When a variable filtration setting was available, lower DAPs were recorded (mean DAP values of $49.2 \mathrm{~Gy} \mathrm{~cm}^{2}$ for variable versus $91.4 \mathrm{~Gy} \mathrm{~cm}^{2}$ for fixed filtration settings $p<0.001)$. The installation of a digital flat panel detector generally resulted in DAPs that were lower than those recorded in image intensifier systems (mean DAP values 


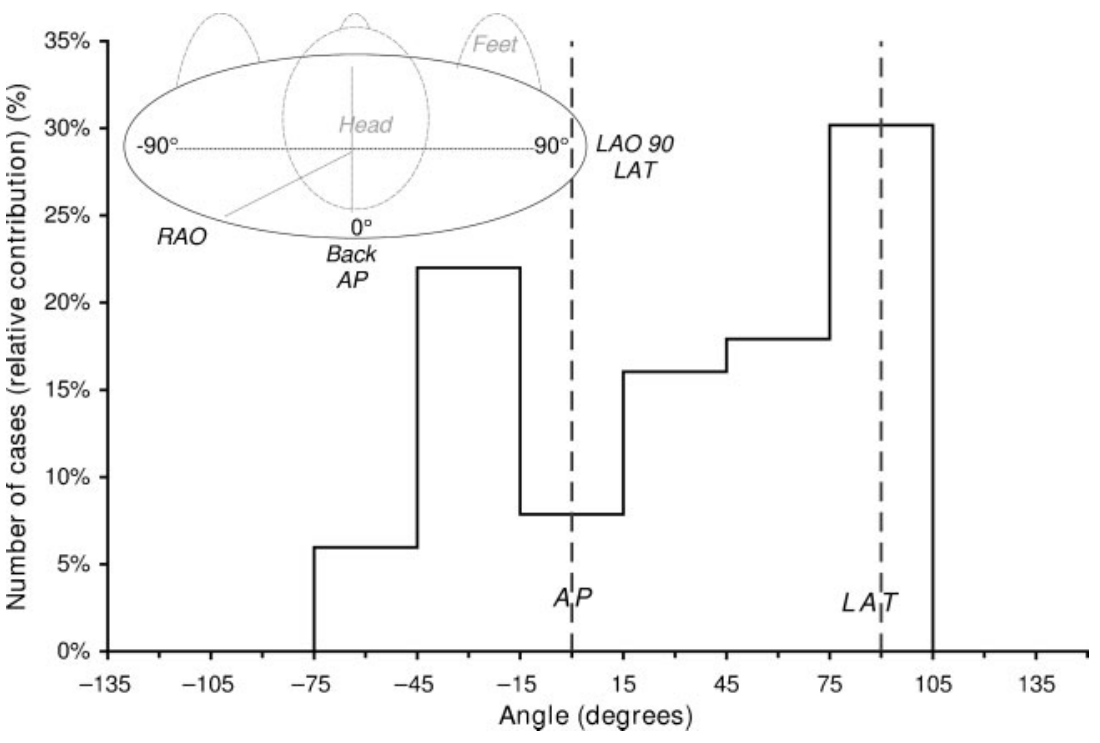

Figure 4. Distribution of the angles under which maximum skin dose (MSD) was received by the patient. The co-ordinate system is centred at the centre of the mathematical cylindrical patient. 0 degrees means anteroposterior (AP) projection and 90 degrees means lateral (LAT) projection.

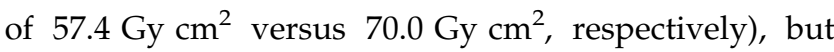
this finding did not reach statistical significance $(p=0.068)$. Apart from the factors just mentioned, the higher DAPs recorded in some hospitals are also due to cardiologists in training performing procedures during the study, and the continuous use of the fluoroscopy high-contrast mode (minimum filtration).

The mean contribution of fluoroscopy to DAP in diagnostic procedures was 33\%, whereas this contribution was $50 \%$ in therapeutic procedures $(p=0.002)$. In general, contributions of fluoroscopy and cine to the total DAP values varied significantly depending on the hospital $(p=0.017)$. The level of procedure difficulty also had a significant influence $(p<0.001)$ with an enhancement of the fluoroscopy contribution in difficult procedures. For diagnostic procedures, hospitals with biplane systems have a significantly larger contribution of cinegraphy than hospitals with a monoplane system $(p=0.001)$. This means that the possibility of acquiring two cinegraphy runs simultaneously at two different projections in a biplane system is not fully exploited but rather leads to an overuse due to the ease and speed of the technique. For therapeutic procedures, these trends are not so prominent.

Figure 5 shows DAP values for diagnostic and therapeutic procedures. The distributions are strongly skewed and the 75th percentile values are indicated by vertical lines. Taking into account the number of catheterisation rooms that were considered, these values are proposed as initial national Belgian DRLs.

\section{Maximum skin dose vs dose area product}

The relation between cumulative DAP and MSD was investigated for both diagnostic and therapeutic interventions based on all hospital data. These data are presented graphically in Figure 6. Different symbols are used to highlight the impact of the difficulty of the procedures. The regression line for bulk data and a trend line for outlying points are indicated. For bulk data, a linear relationship was considered as a first approximation and yielded a $\mathrm{p}<0.001$. The mathematical function $\left(\right.$ c.DAP $\left.{ }^{d}\right)$ chosen for the outlying points was based on their DAP dependence and to fulfil criteria of physical relevance (passing through origin and continuously increasing function). $p$-values for parameters $c$ (0.113) and $\mathrm{d}(0.591)$ were 0.064 ( $p$ slightly $>0.05)$ and lower than 0.001. The fit served as a guiding tool for the derivation of DAP action levels. DAP values of $125 \mathrm{~Gy} \mathrm{~cm}^{2}$ and $250 \mathrm{~Gy} \mathrm{~cm}^{2}$, corresponding to 2 and 3 Gy MSD levels, can be deduced from these data.

\section{Discussion}

\section{Maximum skin dose and dose-area product}

The mean MSDs recorded in this large-scale study, $0.31 \mathrm{~Gy}$ for diagnostic and $0.70 \mathrm{~Gy}$ for therapeutic procedures, confirm the high values for MSD in smaller

Table 3. Summary of the cases in which the maximum skin dose exceeded 2 Gy

\begin{tabular}{|c|c|c|c|c|c|c|c|c|}
\hline $\begin{array}{l}\text { Case } \\
\text { No. }\end{array}$ & Procedure & MSD (Gy) & Angle MSD $\left(^{\circ}\right)$ & $\begin{array}{l}\text { Patient's } \\
\text { gender }\end{array}$ & Cardiologist & DAP $\left(G y \mathrm{~cm}^{2}\right)$ & $\begin{array}{l}\text { Contribution of } \\
\text { fluoro to MSD (\%) }\end{array}$ & $\begin{array}{l}\text { Contribution of cine } \\
\text { to MSD (\%) }\end{array}$ \\
\hline 1 & $\mathrm{D}$ & 2.1 & 100 & $\mathrm{~F}$ & $\mathrm{Tr}+\mathrm{Doc}$ & 194 & 57 & 43 \\
\hline 2 & $\mathrm{~T}$ & 2.5 & -44 & $\mathrm{M}$ & $\operatorname{Tr}$ & 298 & 30 & 70 \\
\hline 3 & $\mathrm{~T}$ & 2.4 & 66 & $\mathrm{M}$ & Doc & 154 & 77 & 23 \\
\hline 4 & $\mathrm{~T}$ & 3.1 & -47 & $\mathrm{M}$ & Doc & 153 & 40 & 30 \\
\hline 5 & $\mathrm{~T}$ & 2.3 & -15 & $\mathrm{M}$ & Doc & 131 & 27 & 73 \\
\hline 6 & $\mathrm{~T}$ & 3.2 & 14 & $\mathrm{~F}$ & $\mathrm{Tr}+\mathrm{Doc}$ & 404 & 95 & 5 \\
\hline 7 & $\mathrm{~T}$ & 3.4 & 45 & $\mathrm{M}$ & Doc & 315 & 98 & 2 \\
\hline 8 & $\mathrm{~T}$ & 4.5 & 95 & $\mathrm{M}$ & Doc & 257 & 89 & 11 \\
\hline 9 & $\mathrm{D}$ & 2.6 & 94 & $\mathrm{~F}$ & Doc & 191 & 79 & 21 \\
\hline
\end{tabular}

D, diagnostic; T, therapeutic; Tr, trainee; Doc, doctor-cardiologist. 
Table 4. Mean values for dose-area product values $\left(\mathrm{Gy} \mathrm{cm}^{2}\right.$ )

\begin{tabular}{|c|c|c|}
\hline & Diagnostic procedures & Therapeutic procedures \\
\hline 1 & 76.9 & 120.3 \\
\hline 2 & 31.2 & 57.0 \\
\hline 3 & 74.2 & 90.8 \\
\hline 4 & 50.6 & 75.8 \\
\hline 5 & 46.2 & 78.0 \\
\hline 6 & 83.1 & 137.7 \\
\hline 7 & 18.6 & 41.5 \\
\hline 8 & 54.9 & 70.0 \\
\hline Dose reference level derived from this study & 71.3 & 106.0 \\
\hline
\end{tabular}

studies published previously: 0.270 Gy [18, 19] for diagnostic procedures and 0.760 Gy [20] and 0.980 Gy [19] for therapeutic procedures. Mean MSDs as low as 0.113 Gy [21] and 0.217 Gy [22] for diagnostic procedures and $0.391 \mathrm{~Gy}$ [22] for therapeutic procedures have also been reported, but these were measured using only a limited number of TLDs, which may explain the differences from the present work. In nine patients, $(3 \%$ of all patients investigated), the dose threshold for deterministic effects to the skin, $2 \mathrm{~Gy}$, was exceeded. This percentage can be considered to be representative for contemporary clinical practice in Belgium.

Mean and median values for cumulative DAP distributions over all patients undergoing diagnostic and therapeutic procedures in this study are within the data ranges reported in the literature. A comparison with literature data can be found in Table $5[18,21,23,24]$.

\section{DAP action levels}

Interpretation of Figure 6 shows that cumulative DAP can serve as a real-time indicator of action levels for MSD. The trend line through the outlying data points results in DAP action levels of $125 \mathrm{~Gy} \mathrm{~cm}^{2}$ and $250 \mathrm{~Gy} \mathrm{~cm}^{2}$ for $2 \mathrm{~Gy}$ and 3 Gy MSD levels, respectively. This trend line is based on the behaviour of outlying MSD values, representing the highest skin doses

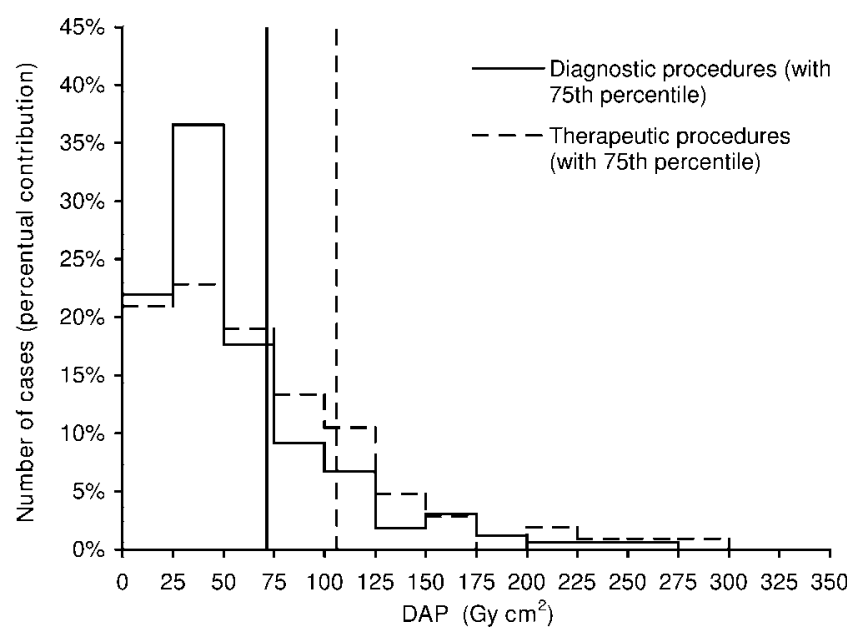

Figure 5. Histogram of dose-area product (DAP) $\left(\mathrm{Gy} \mathrm{cm}^{2}\right)$ for diagnostic (solid line) and therapeutic (dashed line) procedures. The third quartiles are marked by vertical lines and represent the proposed Belgian dose reference levels (DRLs) . obtained in this study. It serves as a guiding tool for the derivation of DAP action levels. The function is not applicable for low DAP values nor for values outside the range of the measured data. It does not represent a general relationship between MSD and DAP as it was based only on outlying points. According to the data in the present study, the cumulative probability of an MSD exceeding the 2 Gy threshold is $30 \%$ when the DAP exceeds the action level of $125 \mathrm{~Gy} \mathrm{~cm}^{2}$. Analogously, the cumulative probability of MSD exceeding the 3 Gy level

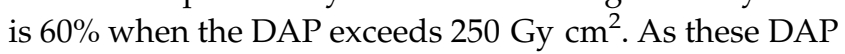
readings can be considered as DAP action levels for both diagnostic and therapeutic procedures, systematic registration of the DAP value at the end of the procedure in the patient's record is indicated.

When the DAP exceeds $125 \mathrm{~Gy} \mathrm{~cm}^{2}$, registration in the patient's record of the entry site of the beam responsible for the highest skin dose (together with the DAP value) is indicated. The cardiologist may also decide whether the patient needs to be followed up for radiation skin effects on the basis of the difficulty of the procedure and the total fluoroscopy time, especially in single projection directions. This decision has to be based on a comparison with the local reference procedure.

At the 3 Gy action level (250 Gy $\left.\mathrm{cm}^{2}\right)$, the patient and his/her personal physician should be informed of the possible radiation effects. In view of the higher probability of skin overexposures in therapeutic interventions, this action level is indicated for therapeutic interventions. In our multicentre study, four interventions (all therapeutic) resulted in skin doses exceeding 3 Gy $(1 \%$ of all procedures or $3 \%$ of the therapeutic interventions). In our study, one patient with a DAP value of $153 \mathrm{~Gy} \mathrm{~cm}^{2}$ and a skin dose of $3.1 \mathrm{~Gy}$ can be considered as a false negative. The DAP action level determined by our study, $250 \mathrm{~Gy} \mathrm{~cm}^{2}$, is somewhat lower than the level resulting from the European DIMOND III project (300 Gy $\mathrm{cm}^{2}$ ) [25].

According to ICRP publication 85 [8], an additional level of $1 \mathrm{~Gy}$ should be considered for procedures that are likely to be repeated. This is applicable to patients undergoing PTCA because a significant number of them need a repeat PTCA or additional coronary procedures. We conclude that a $1 \mathrm{~Gy}$ action level is not relevant as this is only half of the threshold dose and the skin site exposed to the MSD can only be estimated by the cardiologist. A 1 Gy action level would be applicable to a large fraction of the treated patients: in our study $25 \%$ of those undergoing therapeutic procedures. Also, a difference in action level between diagnostic and therapeutic procedures, as recommended by the ICRP, is not relevant 


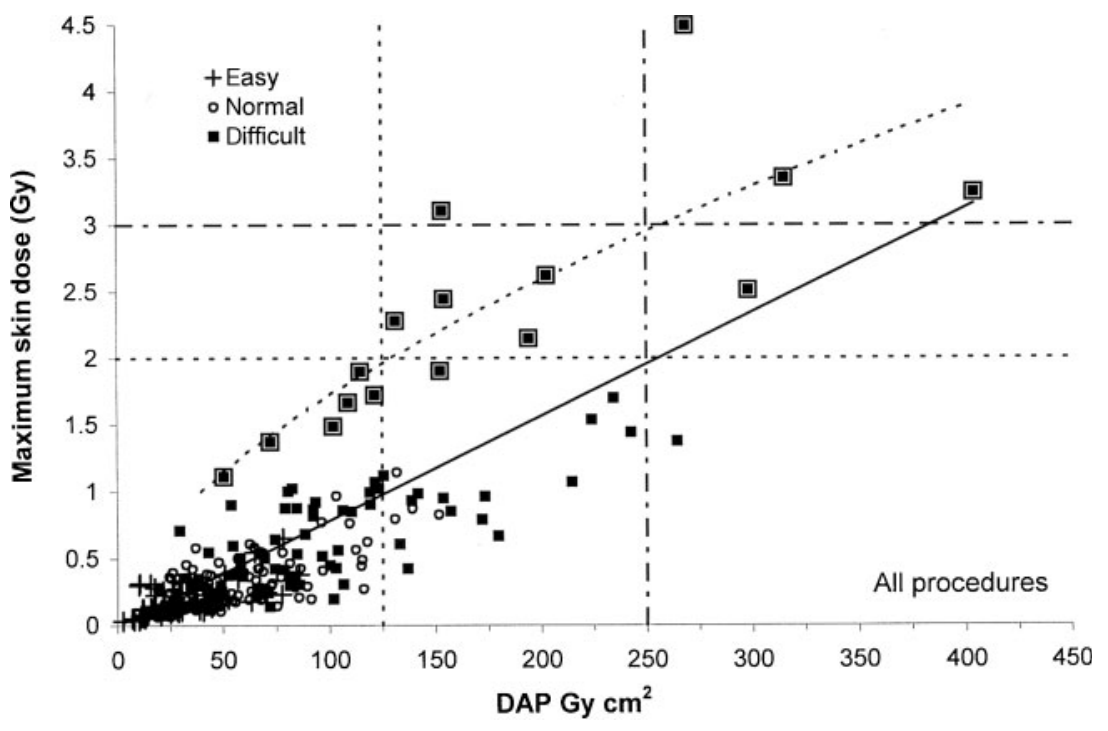

Figure 6. Maximum skin dose (MSD) (Gy) versus dose-area product

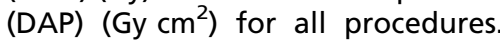
DAP levels of $125 \mathrm{~Gy} \mathrm{~cm}^{2}$ and $250 \mathrm{~Gy} \mathrm{~cm}^{2}$ (vertical lines) correspond to action levels for skin doses of $2 \mathrm{~Gy}$ and $3 \mathrm{~Gy}$, respectively. The different symbols refer to the complexity of the procedure. Outlying points are represented in squared symbols.

as in some hospitals a diagnostic procedure precedes a therapeutic intervention by a few days.

\section{Dose reference levels}

At the end of the EC DIMOND II project in 1999, the following DRLs were proposed: $67 \mathrm{~Gy} \mathrm{~cm}^{2}$ for coronary angiography and $110 \mathrm{~Gy} \mathrm{~cm}^{2}$ for PTCA [26]. The 75th percentile data obtained in present study, $71.3 \mathrm{~Gy} \mathrm{~cm}^{2}$ and $106.0 \mathrm{~Gy} \mathrm{~cm}^{2}$ for diagnostic and therapeutic procedures, respectively, support these DRLs. When applying these reference levels to the mean DAP values from the Belgian hospitals, five of the cardiological centres pass for diagnostic interventions and six for therapeutic interventions. However, a subsequent EC project (DIMOND III, 2003) proposed new DRLs based on the 75th percentiles: $45 \mathrm{~Gy} \mathrm{~cm}^{2}$ for coronary angiography and $75 \mathrm{~Gy} \mathrm{~cm}^{2}$ for PTCA [25]. When applying these more stringent DRLs, only three of the Belgian cardiological centres in our study would pass for diagnostic interventions and four for therapeutic interventions.

In Figure 7, the mean and the 75th percentile values for DAP of diagnostic and therapeutic cardiac interventions obtained in the present Belgian study are compared with the data reported by Neofotistou et al. [25] for different European countries as a result of the European DIMOND III project. It is apparent that DAP values in Belgium are relatively high in comparison with those obtained in other European countries, both for coronary angiography and for therapeutic interventions.

\section{Training programmes and quality control}

The lower reference values of DIMOND III compared with the previously proposed ones were explained by the continued education and training of personnel involved in interventional cardiology procedures and the increase of constancy checks on the X-ray systems. The skin dose distribution data obtained in the present study support practical training programmes dedicated to patient skin dose reduction in interventional cardiology. Besides the emphasis on dose reduction techniques, these programmes should also focus on the relevance of DAP values as guidelines for the optimisation of procedure protocols in terms of radiation protection and prediction of radiation-induced skin injuries. Furthermore, annual quality-control checks on the X-ray equipment should be performed. The systematic registration of DAP for interventional procedures imposed by present Belgian legislation will allow a comparison of hospital DAP values with the DRLs proposed in this paper, and will lead towards the optimisation of radiation exposure. The impact of training programmes and quality control on patient dose will emerge from follow-up on the database of patient DAP values. This will allow updating of the DRLs, very probably to values lower than those presented here and closer to those proposed by DIMOND III.

It must be kept in mind that DAP action levels and DRLs are neither dose constraints nor dose limits. They are investigation tools for the identification of unusually high levels of radiation that call for investigation if substantially exceeded [27].

Table 5. Mean and median dose-area product (DAP) values for diagnostic and therapeutic procedures in interventional cardiology and from data in the literature

\begin{tabular}{|c|c|c|c|c|c|c|}
\hline Reference & Procedure & $\begin{array}{l}\text { Mean DAP } \\
\left(\mathrm{Gy} \mathrm{cm}^{2}\right)\end{array}$ & $\begin{array}{l}\text { Median DAP } \\
\left(\mathrm{Gy} \mathrm{cm}^{2}\right)\end{array}$ & Procedure & $\begin{array}{l}\text { Mean DAP } \\
\left(\mathrm{Gy} \mathrm{cm}^{2}\right)\end{array}$ & $\begin{array}{l}\text { Median DAP } \\
\left(G y \mathrm{~cm}^{2}\right)\end{array}$ \\
\hline Zorzetto et al. [18] & $39 \mathrm{CA}$ & 55.9 & 52.5 & 19 PTCA & 91.8 & 82.6 \\
\hline Vaño et al. [21] & $288 \mathrm{CA}$ & 66.5 & 45.7 & 45 PTCA & 87.5 & 66.7 \\
\hline Padovani et al. [23] & 76 CA-LV & 55.9 & & 54 PTCA & 101.9 & \\
\hline Karambatsakidou et al. [24] & $20 \mathrm{CA}$ & 49.0 & & 40 PTCA & 40.0 & \\
\hline Present work & $200 \mathrm{CA}$ & 55.7 & 43.7 & 118 therap & 81.5 & 65.4 \\
\hline
\end{tabular}

CA, coronary angiography; CA-LV, left catheterism + coronary angiography + left ventriculography + 1-2 other acquisitions; PTCA, percutaneous transluminal coronary angioplasty; therap, therapeutic procedures as defined in present work. 


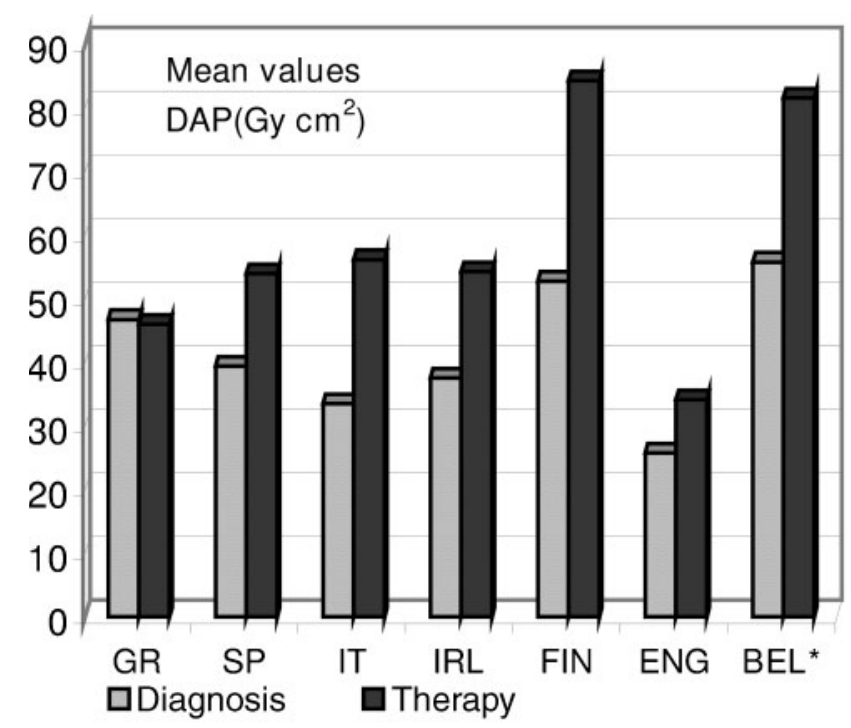

(a)

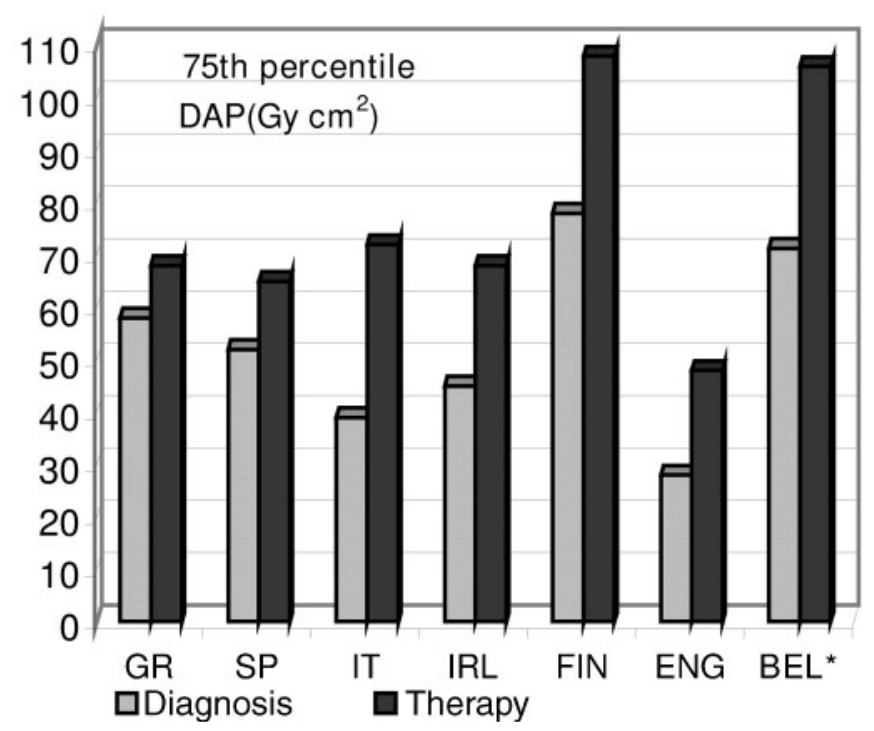

(b)

Figure 7. (a) Comparison of the mean values of the dose-area product (DAP) $\left(\mathrm{Gy} \mathrm{cm}^{2}\right)$ for diagnostic and therapeutic procedures for Belgium ( ${ }^{*}=$ this work) and other EU countries [24]. (b) Comparison of the third quartile values for DAP (Gy $\mathrm{cm}^{2}$ ) for diagnostic and therapeutic procedures for Belgium (* = this work) and other EU countries [24]. BEL, Belgium; ENG, England; FIN, Finland; GR, Greece; IRL, Ireland; IT, Italy; SP, Spain.

\section{Conclusions}

Cumulative DAP can serve as an online monitor to provide the interventionist with an immediately readable dose display representing the MSD. Therefore, systematic registration of this DAP in a patient's record at the end of the procedure is necessary. If DAP exceeds $125 \mathrm{~Gy} \mathrm{~cm}^{2}$ (corresponding to an MSD of $2 \mathrm{~Gy}$ ), registration in the patient's record of the entry site of the beam responsible for the highest skin dose is indicated. Possible follow-up of the patient for radiation skin effects is at the cardiologist's discretion. If DAP exceeds $250 \mathrm{~Gy} \mathrm{~cm}^{2}$ (corresponding to an MSD of $3 \mathrm{~Gy}$ ), the patient and his/her personal physician should be informed of the possible radiation effects. A systematic follow-up should be performed.

In the present study, $71.3 \mathrm{~Gy} \mathrm{~cm}^{2}$ and $106.0 \mathrm{~Gy} \mathrm{~cm}^{2}$ are proposed as national DRLs for diagnostic and therapeutic procedures, respectively, in Belgium. Local mean values should be compared with these values in view of optimisation of patient dose.

The present study supports practical training programmes in interventional cardiology. Besides emphasising dose-reduction techniques, these programmes should also focus on the relevance of DAP as a guide for optimisation of procedure protocols with respect to radiation protection and the prediction of radiationinduced skin injuries.

\section{Acknowledgments}

We acknowledge the Federal Agency for Nuclear Control for financial support and follow-up of the project. The authors wish to thank the nurses, technical personnel and medical staff of catheterisation departments of all the hospitals involved in this study for their participation and their help with patient skin dose measurements. N. Reynaert of the Standard Dosimetry
Laboratory in Ghent is acknowledged for practical help with TLD calibration. We express special thanks to V. de Gelder, A. De Hauwere, J. Lauwaert, B. Vanderstraeten for their help and their practical support in with measurements and data analysis.

\section{References}

1. Shope TB. Radiation-induced skin injuries from fluoroscopy. Radiographics 1996;16:1195-9.

2. Wagner LK, Eifel PJ, Geise RA. Potential biological effects following high $\mathrm{X}$-ray dose interventional procedures. J Vasc Interv Radiol 1994;5:71-84.

3. FDA Public Health Advisory. Avoidance of serious X-rayinduced skin injuries to patients during fluoroscopicallyguided procedures. http://www.fda.gov/cdrh/fluor.html. 1994.

4. Koenig TR, Wolff D, Mettler FA, Wagner LK. Skin injuries from fluoroscopically guided procedures: part I, characteristics of radiation injury. AJR Am J Roentgenol 2001;177:3-11.

5. Koenig TR, Mettler FA, Wagner LK. Skin injuries from fluoroscopically guided procedures: part 2, review of 73 cases and recommendations for minimizing dose delivered to patient. AJR Am J Roentgenol 2001;177:13-20.

6. Kuon E, Glaser C, Dahm JB. Effective techniques for reduction of radiation dosage to patients undergoing invasive cardiac procedures. Br J Radiol 2003;76:406-13.

7. Hirshfeld JW, Balter SD, Brinker JA, Kern MJ, Klein LW, Lindsay BD et al. ACCF/AHA/HRS/SCAI clinical competence statement on physician knowledge to optimize patient safety and image quality in fluoroscopically guided invasive cardiovascular procedures - a report of the American College of Cardiology Foundation/American Heart Association/American College of Physicians Task Force on Clinical Competence and Training. Circulation 2005;111:511-32.

8. ICRP. Recommendations of the International Commission on Radiological Protection. Publication 85: Avoidance of radiation injuries from medical interventional procedures. Ann. ICRP. Oxford, UK: Pergamon Press 2000: 30. 
9. Vaño E, Gonzalez L, Ten JI, Fernandez JM, Guibelalde E, Macaya C. Skin dose and dose-area product values for interventional cardiology procedures. $\mathrm{Br} \mathrm{J}$ Radiol 2001;74:48-55.

10. Neofotistou V, Karoussou A, Lobotesi H, Hourdakis K. Patient dosimetry during interventional cardiology procedures. Radiat Prot Dosim 1998;80:151-4.

11. Betsou S, Efstathopoulos EP, Katritsis D, Faulkner K, Panayiotakis G. Patient radiation doses during cardiac catheterization procedures. Br J Radiol 1998;71:634-9.

12. Suzuki S, Furui S, Kohtake H, Yokoyama N, Kozuma K, Yamamoto $Y$, et al. Radiation exposure to patient's skin during percutaneous coronary intervention for various lesions, including chronic total occlusion. Circ J 2006; 70:44-8.

13. Marshall NW, Chapple CL, Kotre CJ. Diagnostic reference levels in interventional radiology. Phys Med Biol 2000; 45:3833-46.

14. Grosswendt B. Conversion coefficients for calibrating individual photon dosimeters in terms of dose equivalents defined in an ICRU tissue cube and PMMA slabs. Radiat Prot Dosim 1990;32:219-31.

15. Olson CL. Comparative robustness of 6 tests in multivariateanalysis of variance. J Am Stat Assoc 1974;69:894-908.

16. Research Development Core Team. A language and environment for statistical computing. Research Foundation for Statistical Computing, Vienna, Austria. ISBN 3-900051-07-0; http://www.R-project.org. 2008.

17. Kuon E, Dahm JB, Empen K, Robinson DM, Reuter G, Wucherer M. Identification of less-irradiating tube angulations in invasive cardiology. J Am Coll Cardiol 2004;44:1420-8.

18. Zorzetto M, Bernardi G, Morocutti G, Fontanelli A. Radiation exposure to patients and operators during diagnostic catheterization and coronary angioplasty. Catheter Cardiovasc Diagn 1997;40:348-51.

19. Hansson B, Karambatsakidou A. Relationships between entrance skin dose, effective dose and dose area product for patients in diagnostic and interventional cardiac procedures. Radiat Prot Dosim 2000;90:141-4.

20. van de Putte S, Verhaegen F, Taeymans Y, Thierens H. Correlation of patient skin doses in cardiac interventional radiology with dose-area product. Br J Radiol 2000;73: 504-13.

21. Vaño E, Gonzalez L, Fernandez JM, Guibelalde E. Patient dose values in interventional radiology. $\mathrm{Br} \mathrm{J}$ Radiol 1995;68:1215-20

22. Vaño E, Goicolea J, Galvan C, Gonzalez L, Meiggs L, Ten JI, et al. Skin radiation injuries in patients following repeated coronary angioplasty procedures. Br J Radiol 2001;74: 1023-31.

23. Padovani R, Novario R, Bernardi G. Optimisation in coronary angiography and percutaneous transluminal coronary angioplasty. Radiat Prot Dosim 1998;80:303-6.

24. Karambatsakidou A, Tornvall $P$, Saleh N, Chouliaras $T$, Lofberg P, Fransson A. Skin dose alarm levels in cardiac angiography procedures: is a single DAP value sufficient? Br J Radiol 2005;78:803-9.

25. Neofotistou V, Vaño E, Padovani R, Kotre J, Dowling A, Toivonen $\mathrm{M}$, et al. Preliminary reference levels in interventional cardiology. Eur Radiol 2003;13:2259-63.

26. Lobotessi H, Karoussou A, Neofotistou V, Louisi A, Tsapaki $\mathrm{V}$. Effective dose to a patient undergoing coronary angiography. Radiat Prot Dosim 2001;94:173-6.

27. European Commission Council Directive of 30 June 1997 (97/43/Euratom) on Health Protection of Individuals against the Dangers of Ionising Radiation in relation to Medical Exposure. Official J Eur Commun 1997;180:22-7. 